\title{
Associations Among Depression, Leisure-time and Occupational Physical Activity of Health Care Providers in a Nigerian Tertiary Hospital Setting
}

\author{
Aliyu E.S., ${ }^{1}$ Adeniyi A.F. ${ }^{2}$ \\ ${ }^{1}$ Department of Physiotherapy, University of Abuja Teaching Hospital, Gwagwalada, Abuja, Nigeria \\ ${ }^{2}$ Department of Physiotherapy, College of Medicine, University of Ibadan/University College Hospital, Ibadan, \\ Nigeria \\ Correspondence \\ E.S. Aliyu - shalomemmy@gmail.com
}

SUMMARY

Physical activity (PA) has been consistently associated with enhanced quality of life. The tight schedule of duty of health care workers may predispose them to physical inactivity and psychosocial morbidities which most of them tend to ignore while rendering services to others. The prevalence of depression among Nigerian health care workers and its association with PA is not known. This study investigated the levels of leisure-time and occupational PA and their association with depression among health care providers in a Nigerian tertiary hospital setting.

The research was a cross-sectional survey of 734 health care providers. The Godin-Shephard Leisure Time Physical Activity Questionnaire, Occupational Physical Activity Questionnaire and the Depression Anxiety and Stress Scale were used to assess leisure-time PA, occupational PA and depression respectively. Data obtained were analysed using descriptive and inferential statistics at $\alpha=0.05$.

The mean age of participants was $39.6 \pm 9.4$ years (range 22-57 years). Nearly half of the health care providers (46.2\%) reported low participation or insufficient leisure-time PA that could provide substantial health benefits, while $20.2 \%$ participated in leisure-time PA that could give some health benefits and $33.7 \%$ participated in leisure-time PA that could give substantial health benefits. Sitting/standing were the main occupational PAs of the majority $(96.2 \%)$ of the health workers. The overall prevalence for depression was $11.4 \%$. There was a significant association between leisure-time PA and depression $\left(\chi^{2}=18.9, p=0.016\right)$. There was no significant association between occupational PA and depression.

There is low participation in leisure-time PA among health care workers and this is linked with depression. Efforts to improve participation in leisure-time PA among workers may help to relieve their depression symptoms.

KEY WORDS: leisure time, occupation, physical activity, depression

\section{INTRODUCTION}

Physical activity (PA) has been consistently associated with enhanced quality of life which is conceptualized as representing physical, mental, psychosocial or healthrelated quality of life (Stewart and King, 1991). With reference to older adults, a number of physical and psychosocial factors might represent mental and physical health status outcomes: strength, power, functional limitation, agility, balance and coordination (Siobhan et al., 2009). For example, according to Elavsky and colleagues 
(2005), self-esteem has consistently been shown to be influenced by PA.

The work place has been defined by the European Agency for Safety and Health at Work (EU-OSHA, 2008) as any place where physical and/or mental labour occurs whether paid or unpaid. This includes formal work sites, private homes, vehicles or outdoor locations on public or private property. Workplace health promotion has generally focused on promoting workers' health through reduction of individual risk-related behaviour such as sedentary lifestyle, stressors and reactions to them and other preventable health behaviours (O'Donnell, 2002). It was also stated by Engbers et al (2005), that the work health promotion programmes are an effective means of promoting healthy and regular PA.

Celano and Huffman (2011) opined that negative psychosocial attributes such as depression play an important role in the development and progression of some diseases. For example patients who suffer depression are more likely to develop and die from cardiac disease than those without depression, independent of traditional cardiac risk factors (Celano and Huffman, 2011). Moraska and Fleshner (2001) have shown that moderate PA can prevent stress-induced behavioural depressions and immune suppression.

Most health workers sometimes neglect their own health in the course of rendering health care services. This was shown in a PA study among health professionals in South Africa conducted by Skaal and Pengpid (2011), in which they reported that in South Africa, sedentary lifestyles were observed more frequently among health professionals working in urban settings. The study revealed that the majority $(75 \%)$ of hospital staff, both medical and support staff, were overweight/obese, even though $57 \%$ of them perceived themselves to be of normal weight. Skaal and Pengpid (2011) added that health care workers are perceived to be pioneers of healthy lifestyles, and although the communities expect them to lead by example, their study revealed that health care workers are a high-risk group for non-communicable diseases, and that working conditions lead to their physical inactivity. This was also observed in the study carried out by Richardsen et al (1992) at a hospital in Northern Norway, in which they found that anxiety, emotional exhaustion and job stress resulted in job burnouts among the health care workers.

Reports on the prevalence of depression problems among Nigerian health care workers and its association with PA appear to be sparse. There was therefore a need to investigate the burden of depression among health care workers in a Nigerian setting and to investigate how this is connected to their occupational and leisure-time PA participation. This study thus sought to answer the following questions: what is the prevalence of depression and the levels of leisure-time and occupational PA among health care providers in a Nigerian hospital setting? Would there be any association between leisure-time PA, occupational PA and depression among health care providers?

\section{METHODS}

\section{Participants}

Participants in this cross-sectional study were health care providers in the employment of the University of Abuja Teaching Hospital (UATH), Gwagwalada, Abuja. The teaching hospital is a 396-bed tertiary health care institution located in the Federal Capital Territory, Abuja, Nigeria. The hospital is structured into three large divisions of clinical services which comprises all the clinical departments; nursing services and the administration division. The participants for this study were drawn from the clinical services division. They comprised a total of 734 personnel made up of medical doctors, nurses, pharmacists, physiotherapists, radiographers, medical laboratory scientists, medical laboratory technologists/technicians, optometrists, clinical psychologists, dental therapists and dental technologists. Only the health care providers of UATH who were on the nominal roll of the hospital and had been working for at least six months prior to the commencement of the study were allowed to participate in this study. Health care providers who had medical conditions such as lower limb amputation, spinal cord injury and other physical disabilities that could have prevented them from participating in any PA were excluded from the study. Participants for the study were all consenting health care providers of UATH.

\section{Instruments for Data Collection \\ Godin-Shephard Leisure Time Physical Activity Questionnaire (GLTPAQ)}

Developed by Godin and Shephard, this 4-item questionnaire allows the assessment of self-reported leisuretime PA of strenuous exercise, moderate exercise, mild exercise and working up a sweat (Godin, 2011). Score was expressed in units and was computed in two steps. First, weekly frequencies of strenuous, moderate and mild activities were multiplied by 9,5 and 3 respectively (Godin, 2011). Then the total weekly leisure activity score was 
computed in units by summing the products of the separate components as shown in the following formula:

Weekly leisure-time activity score $=$

$(9 \times$ strenuous $)+(5 \times$ moderate $)+(3 \times$ mild $)$

According to Godin (2011), in computing the scores to assess for the health benefits that can be obtained from participation in leisure-time PA, for units obtained using only moderate and strenuous PA, the following rules can be adopted:

- 24 units or more: Active (substantial benefits)

- 14 to 23 units: moderately active (some benefits)

- Less than 14 units: insufficiently active (less substantial or low benefits)

The validation study (Godin and Shephard, 1985) indicated correlation values between the questionnaire and percentile $\mathrm{VO}_{2} \max (\mathrm{r}=0.24, \mathrm{P}<0.001)$ and percentile body fat $(\mathrm{r}$ $=13, \mathrm{P}<0.01)$. The test-retest reliabilities were moderate $(\mathrm{r}=0.30-0.45)$ for the mild and moderate exercise categories and moderate $(r=0.50-0.60)$ for the strenuous exercise category and the total leisure activity score. Overall, the strength of the reliability coefficient was moderate $(r=0.62)$.

\section{Occupational Physical Activity Questionnaire (OPAQ)}

Designed by Reis et al (2005) to measure PA specifically during paid employment. It is a 7-point self-report questionnaire that measures occupational sitting/standing, walking, and heavy labour. It tests for total activity and sedentary activity while at work. The correlation coefficient is as follows: ICC $(95 \% \mathrm{CI})=0.76(0.59 ; 0.86)$ for total activity and ICC $(95 \% \mathrm{CI})=0.78(0.62 ; 0.87)$ for sedentary activity (Reis et al, 2005). It is scored as mostly sitting/standing, mostly walking, or mostly heavy labour, depending on which of the activities has the highest number of hours reported.

\section{Depression Anxiety and Stress Scale (DASS)}

The DASS questionnaire was developed by Lovibond and Lovibond in 1983 (Nieuwenhuijsen et al, 2003). It is a 42item questionnaire that includes three self-report scales designed to measure the negative psychosocial states of depression, anxiety and stress. The internal consistency for each of the DASS subscales has been shown to be high with Chronbach's alpha of $0.94,0.88$ and 0.93 for depression, anxiety and stress respectively. Construct validity was further supported by moderately high correlations of the DASS with indices of convergent validity $(0.63$ and 0.75$)$, and lower correlations of the DASS with indices of divergent validity (range -0.22 to 0.07 ) (Nieuwenhuijsen et al, 2003). Each of the three scales contains 14 items, divided into subscales of 2-5 items with similar content. The depression scale assesses dysphoria, hopelessness, devaluation of life, self-deprecation, lack of interest / involvement, anhedonia, and inertia. The depression scale items on the questionnaire are items $3,5,10,13,16,17,21$, 24,26,31,34,37,38,42.

The participants' sociodemographic and work-related data, including age, sex, years of experience, typical work duration per day (in hours), were also documented. All the questionnaires were self-report and administered to consenting participants in each department at the same time.

\section{Procedure}

Ethical approval of the University of Ibadan/University College Hospital Research Ethics Review Committee was sought and obtained prior to commencement of the study. In addition, the approval of the management of University of Abuja Teaching Hospital was also obtained. Written informed consent was also sought and obtained from the participants after the purpose and procedures of the study had been explained to them. All the questionnaires were administered to consenting participants by department at the same time and the researcher waited to collect the duly completed questionnaires.

\section{Data Analysis}

Socio-demographic data was presented in the form of frequency tables. Using SPSS version 21, chi square statistics with the alpha value set at 0.05 , was used to analyse the association between depression and each of leisure-time and occupational PA.

\section{RESULTS}

Overall, a total of 734 health staff of the University of Abuja Teaching Hospital (UATH) were recruited into this study. The mean age was $39.6 \pm 9.4$ years (range $22-57$ years). There were more females $(61.4 \%)$ than males. The majority of the participants were nurses $(48.5 \%)$ followed by doctors $(34.2 \%)$ (table 1$)$.

\section{Leisure-time and Occupational PA among Health Care Providers}

Table 2 shows that $46.2 \%$ of the participants had leisuretime PA of less than 14 units (less substantial or low benefits), $20.2 \%$ between 14-23 units (some benefits) and 
$33.7 \%$ more than 23 units (substantial health benefits). The majority of the health workers $(96.2 \%)$ mostly sit or stand at work. None of the health workers reported engaging in activities that involve mostly heavy labour such as using power tools, moving furniture or jackhammers. Mean number of hours per week spent sitting/standing (28.6 \pm 5.0) and walking (18.0 \pm 5.6) differed significantly $\left(\chi^{2}=10.62, \mathrm{p}<0.0001\right)($ table 3$)$.

Table 1. Socio-demographic characteristics of the respondents

\begin{tabular}{|c|c|c|}
\hline Variable & Frequency & Percentage \\
\hline \multicolumn{3}{|l|}{ Age (years) } \\
\hline$<30$ & 178 & 24.3 \\
\hline $30-39$ & 183 & 26.3 \\
\hline $40-49$ & 295 & 29.4 \\
\hline$\geq 50$ & 147 & 20.0 \\
\hline Range & $22-57$ & \\
\hline Mean \pm SD & $39.6 \pm 9.4$ & \\
\hline \multicolumn{3}{|l|}{ Sex } \\
\hline Male & 283 & 38.6 \\
\hline Female & 451 & 61.4 \\
\hline \multicolumn{3}{|l|}{ Years of experience } \\
\hline$<15$ & 407 & 55.4 \\
\hline $15-19$ & 66 & 9.0 \\
\hline $20-24$ & 144 & 19.6 \\
\hline$>24$ & 117 & 15.9 \\
\hline Range & $1-34$ & \\
\hline Mean \pm SD & $13.4 \pm 9.4$ & \\
\hline \multicolumn{3}{|l|}{ Work duration per day (hours) } \\
\hline 5 & 9 & 1.2 \\
\hline 8 & 717 & 97.7 \\
\hline 12 & 8 & 1.1 \\
\hline \multicolumn{3}{|l|}{ Professional category } \\
\hline Nurse & 356 & 48.5 \\
\hline Pharmacist & 31 & 4.2 \\
\hline Physiotherapist & 26 & 3.5 \\
\hline Laboratory scientist & 30 & 4.1 \\
\hline Radiographer & 13 & 1.8 \\
\hline Optometrist & 8 & 1.1 \\
\hline Clinical psychologist & 9 & 1.2 \\
\hline Dental therapist/technologist & 10 & 1.4 \\
\hline Doctors & 251 & 34.2 \\
\hline
\end{tabular}

Table 2. Leisure-time and Occupational physical activity among health workers in UATH

\begin{tabular}{lcc}
\hline Variable & Frequency & Percentage \\
\hline Leisure-time physical activity (units) & & \\
$<14$ (Less substantial or low benefits) & 339 & 46.2 \\
14-23 (Some health benefits) & 148 & 20.2 \\
>23(Substantial health benefits) & 247 & 33.7 \\
Occupational physical activity & & \\
Mostly sitting/standing & 667 & 96.2 \\
Mostly walking & 26 & 3.8 \\
Mostly heavy labour & 0 & 0.0 \\
\hline
\end{tabular}

Table 3. Occupational physical activity (mean time) among health workers in UATH

\begin{tabular}{lccc}
\hline Variable & Mean $\pm \mathrm{SD}$ & $\mathrm{t}$ & $\mathrm{p}$-value \\
\hline Occupational physical & & & \\
activity & $($ Hours/week $)$ & & \\
Mostly sitting/standing & $28.6 \pm 5.0$ & 10.62 & $<0.0001$ \\
Mostly walking & $18.0 \pm 5.6$ & & \\
\hline
\end{tabular}

Prevalence of depression among health care providers

The overall prevalence of depression among the health care providers was $11.4 \% ; 6.1 \%$ reported mild depression, $2.5 \%$ moderate depression, $2.7 \%$ severe depression and $0.1 \%$ extremely severe depression (table 4 ).

Table 4. Depression among health workers in UATH

\begin{tabular}{lrc}
\hline Variable & Frequency & Percentage \\
\hline Depression & & \\
$0-9$ (Normal) & 650 & 88.6 \\
$10-13$ (Mild) & 45 & 6.1 \\
14-20 (Moderate) & 18 & 2.5 \\
$21-27$ (Severe) & 20 & 2.7 \\
$>27$ (Extremely severe) & 1 & 0.1 \\
\hline
\end{tabular}

Association of depression with leisure-time and occupational PA of the health care providers

Table 5 shows that a significant association exists between depression and the leisure-time activity of the healthcare providers. There was no significant association between depression and the occupational PA of the health care providers (table 6).

Table 5. Association between leisure-time physical activity and depression

\begin{tabular}{|c|c|c|c|c|c|c|c|}
\hline \multirow{2}{*}{$\begin{array}{l}\text { Leisure time-physical } \\
\text { activity }\end{array}$} & \multicolumn{5}{|c|}{ Depression } & \multirow[t]{2}{*}{$\chi^{2}$} & \multirow[t]{2}{*}{ p-value } \\
\hline & Normal & Mild & Moderate & Severe & $\begin{array}{l}\text { Extremely } \\
\text { severe }\end{array}$ & & \\
\hline Active & $220(89.1 \%)$ & $17(6.9 \%)$ & $10(4.0 \%)$ & $0(0.0 \%)$ & $0(0.0 \%)$ & & \\
\hline Moderately active & $131(88.5 \%)$ & $11(7.4 \%)$ & $0(0.0 \%)$ & $6(4.1 \%)$ & $0(0.0 \%)$ & 18.9 & $0.016^{*}$ \\
\hline Insufficiently active & $299(88.2 \%)$ & $17(5.0 \%)$ & $8(2.4 \%)$ & $8(2.4 \%)$ & $1(0.3 \%)$ & & \\
\hline
\end{tabular}

Alpha value $=0.05 ; *$ shows significance 
Table 6. Association between occupational physical activity and depression

\begin{tabular}{|c|c|c|}
\hline \multirow[t]{2}{*}{ Occupational physical activity } & \multicolumn{2}{|c|}{ Depression } \\
\hline & No & Yes \\
\hline Mostly sitting/standing & $591(88.6)$ & $76(11.4)$ \\
\hline Mostly walking & $23(88.5)$ & $3(11.5)$ \\
\hline$\chi^{2}$ & 0.01 & \\
\hline $\mathrm{P}$ & 0.98 & \\
\hline
\end{tabular}

Alpha value $=0.05$

* shows significance

\section{DISCUSSION}

The results of this study showed that almost half of the health care providers in UATH were insufficiently active with respect to level of leisure-time PA that was substantial enough to give health benefits. This low participation in leisure-time PA may be due to the busy schedule of these health care providers in rendering health care services. It may also be due to the fact that the majority of the health care providers perceived themselves as healthy because they are involved in health care delivery and as such may not need any form of leisure-time PA. The findings of this study carried out among Nigerian health workers seem to differ from what was observed among health workers in other countries. It was reported by Li et al (2014) that the level of leisure-time PA among public hospital employees in Shanghai, China, was significantly high. It is also in contrast to a study carried out by Elin et al (2013), in which it was reported that of the population studied in Sweden $(2,875), 82 \%$ were health workers and more than half of them reported a good level of leisure-time PA, and this enabled them to perform better in their work place. However, the findings of this study agree with the study carried out by Elzibieta at al (2012), in which low levels of leisure-time PA were reported among doctors, nurses and other health personnel in Warsaw, Poland. Similarly Rady and Sabbour (1997) also reported that among 616 physicians employed in the Faculty of Medicine at Ain Shams University, Cairo, Egypt, $84 \%$ were sedentary. From the findings of Frank and Segura (2009), it was also reported that in Canada, physicians did not fulfil the guideline recommended by the American College of Sports Medicine and American Heart Association, which was 30 minutes or more of moderate or vigorous exercises daily.

The majority of the health workers mostly sit or stand at work while a small proportion walk on most occasions when at work. The work or schedule of the health care providers involves attending to patients - taking blood pressure, pulse rate, respiratory rate (nurses), taking blood samples and carrying out investigations (laboratory scientists/technologists), treating patients (doctors, nurses, physiotherapists), taking history and counselling patients (doctors, nurses, physiotherapists, etc.). Most of these duties involve either sitting or standing. This may be the reason why most of the participants reported their occupational PA as either mostly sitting/standing. This was in consonance with the findings in the study by Steele and Mummery (2003), who reported a low level of walking during work among professionals as compared to a higher level of walking (highly active) among blue collar workers.

Findings from this study revealed that the prevalence of depression among the health care providers was $11.4 \%$. This may be due to many reasons, but the fact that close to half of the health care providers' reported low participation in leisure-time PA cannot be overlooked. Craft and Landers (1998) and Lawlor and Hopker (2001) had reported that PA (exercises) help in reducing depression. The findings from this study agree with findings from the study by Williams et al (2002) in which they reported that PA reduces the risk of depression in older adults.

\section{CONCLUSION/RECOMMENDATIONS}

There is a substantial level of low participation in leisuretime PA among the health care workers. This is linked with depression. Efforts to improve participation in leisure-time PA among the workers would enhance their psychosocial health. Policies that will encourage health care providers to participate in leisure-time PA should be put in place. Also, facilities and enabling environment for leisure-time PA should be made available in the work place of health care providers.

\section{ACKNOWLEDGEMENTS}

The authors immensely appreciate the management and staff of University of Abuja Teaching Hospital (UATH), Gwagwalada Abuja, Nigeria, for the assistance and cooperation in carrying out this research. The authors are also grateful to Dr. Yetunde Adeniyi (Consultant Psychiatrist, University College Hospital, Ibadan, Nigeria), for her advice and contributions to the success of this study.

FUNDING: This study was self-funded.

DECLARATION: The authors declare that this work is the original work of the authors and the authors declare no conflict of interest. 


\section{References}

Cairney J., Kwan M.Y., Veldhuizen S. and Faulkner G.E.J. 2014. Who uses exercise as a coping strategy for stress? Results from a national survey of Canadians. Journal of Physical Activity and Health 11(5): 908-16.

Celano C.M. and Huffman J.C. 2011. Depression and cardiac disease: A review. Cardiology Review 19(3): 130-142.

Dishman R.K., Warren J.M., Youngstedt S.D., Yoo H., Bunnell B.N., Mougey E.H., Meyerhoff J.L., Jaso-Friedmann L. and Evans D.L. 1995. Activity-wheel running attenuates suppression of natural killer cell activity after foot shock. Journal of Applied Physiology 78: 1547-1554.

Dishman R.K., Warren J.M., Hong S., Bunnell B.N., Mougey E.H., Meyerhoff J.L., Jaso-Friedmann L. and Evans D.L. 2000. Treadmill exercise training blunts suppression of splenic natural killer c-cell cytolysis after footshock. Journal of Applied Physiology 88: 2176-2182.

Dunn A.L., Trivedi M.H. and O'Neil H.A. 2000. Physical activity dose-response effects on outcomes of depression and anxiety. Medicine and Science in Sports Exercise 33: 587-597.

Elin A., Mats B., Gunner A., Agneta L. and Ingiborg H.J. 2013. The level of leisure-time physical activity is associated with work ability - a cross sectional and prospective study of health care workers. BMC Public Health 13: 855.

Elavsky S., Mc Auley E., MoH R., Konopack J.F., Marquez D.X., Hu L., Jenme G.J. and Diener E. 2005.Physical activity enhances long-term quantity of life in older adults: Efficacy, esteem and affective influences. Annals of Behavioural Medicine 30(2): 138-145.

Elzbieta B., Anna P. and Antoni K.G. 2012. Is physical activity of medical personnel a role model for their patients? Annals of Agricultural and Environmental Medicine 19(4): 707-710.

Engbers, L.H., van Poppel M.N., Paw Chin A. and van Mechelen W. 2005. Work site health promotion program with environmental changes. A systematic review. American Journal of Preventive Medicine 29(1): 61-70.

EU-OSHA. 2008. European Agency for Safety and Health at Work. A European campaign on risk assessment. Campaign summary.

http://osha.eurpa.ev/en/campaign/hw2008/campign/campaign summary/.

Frank E. and Segura C. 2009. Health practices of Canadian physicians. Canadian Family Physicians 55: 810-811.

Godin G. 2011. The Godin-Shephard Leisure-Time Physical Activity Questionnaire. Health and Fitness Journal of Canada 4(1): 18-22.

Godin G. and Shephard R.J. 1985. A simple method to assess exercise behaviour of employees. A validity study. Journal of Occupational Medicine 31: 969-973.

Lawlor D.A. and Hopker S.W. 2001. The effectiveness of exercise as an intervention in the management of depression: systematic review and meta-regression analysis of randomized control trials. British Medical Journal 322: 763-767.

Li X., Cheng M., Zhang H., Ke T. and Chen Y. 2014. Prevalence and determination of physical inactivity among public hospitals employees in Shanghai China: A cross-sectional study. Frontiers in Medicine 9(1): 100-107.

Lynette L.C. and Frank M.P. 2004. The benefits of exercise for the clinically depressed. Journal of Clinical Psychiatry 6: 104-111.

Moraska A. and Flesher M. 2001. Voluntary physical activity prevents stress- induced behavioral depression and anti-KLH antibody suppression. American Journal of Physiology Regulatory Integrative and Comparative Physiology 281: R484- R489.

Nieuwenhuijsen K., de Boer AGEM., Verbeek J.H.A.M., Blonk R.W.B. and Van Dijk F.J.H. 2003. The Depression Anxiety Stress Scales (DASS): Detecting anxiety disorder and depression in employees absent from work because of mental health problems. Occupational and Environmental Medicine 60(suppl 1): i77-i82.

O'Donnell M.P. (ed.) 2002. Health Promotion in the Workplace, 3rd ed. Toronto, ON: Delmar Thomson Learning.

Rady M. and Sabbour S.M. 1997. Behavioural risk factors among physicians working at faculty of medicine - Ain Shams University. Journal of Egypt Health Association 72: 233-56.

Reis J.P., Dubose K.D., Ainsworth B.E., Macera C.A. and Yore M.M. 2005. Reliability and validity of the Occupational Physical Activity Questionnaire. Medicine and Science in Sports Exercise 37(12): 2075-83.

Richardsen A.M., Burke R.J., Leiter M. 1992. Occupational demands, psychological burnout and anxiety among hospital personnel in Norway. Anxiety, Stress \& Coping 5(1): 55-68. Published online in 2007.

Siobhan M.W., Thomas R.W. and Edward M. 2009. Health and Quality of Life Outcomes 7: 10.

Skaal L. and Pengpid S. 2011. Physical activity, fitness level and health problems of healthcare workers in South Africa: The transtheoretical model as an explanatory frame work. African Journal for Physical, Health Education, Recreation and Dance 17(4:1): 612-623.

Steele R. and Mummery K. 2003. Occupational physical activity across occupational categories. Journal of Science and Medicine in Sport 6(4): 398-407.

Stewart A. and King A. 1991. Evaluating the efficacy of physical activity for influence quality of life outcomes in older adults. Annals of Behavioural Medicine 13(3): 108-116.

William J.S., Stephane D., Roberts E.R. and George A.K. 2002. Physical activity reduces the risk of subsequent depression for older adults. American Journal of Epidemiology 156(4). 